\title{
Thermal behavior of BST//PVDF ceramic-polymer composites
}

\author{
Katarzyna Osińska $\cdot$ Dionizy Czekaj
}

Received: 8 October 2012/Accepted: 31 January 2013/Published online: 13 March 2013

(C) The Author(s) 2013. This article is published with open access at Springerlink.com

\begin{abstract}
In this paper, we report the results of a study of microstructure and thermal behavior of ceramic-polymer composites composed of barium strontium titanate $\mathrm{Ba}_{0.6} \mathrm{Sr}_{0.4} \mathrm{TiO}_{3}$ (BST60/40) and polyvinylidene fluoride (PVDF). The $\mathrm{Ba}_{0.6} \mathrm{Sr}_{0.4} \mathrm{TiO}_{3}$ ceramic powder was prepared by the sol-gel method. Thermal evolution of the dried gel as well as ceramic powder was studied by simultaneous thermal analysis. The composite BST60/40//PVDF was obtained by hot pressing method for volume fraction of BST60/40 ceramic powder $c_{\mathrm{v}}=50 \%$. The morphology of BST60/40//PVDF composite powder was observed by transmission electron microscopy and the morphology of BST60/40//PVDF composite sample was observed by scanning electron microscopy. Temperature dependence of dielectric constant and dielectric loss factor of BST60/40// PVDF composites was measured in the frequency range of $f=\left(10 \times 10^{3}-1 \times 10^{6}\right) \mathrm{Hz}$. Dynamic mechanical properties of BST60/40//PVDF composites were measured by dynamic mechanical thermal analysis DMTA.
\end{abstract}

Keywords Composite $\cdot$ BST//PVDF . Thermal properties

\section{Introduction}

Composite technology in general sets out to combine materials in such a way that the properties of the composite are the optimum for a particular application. The property, whether mechanical, thermal, electrical, etc., is determined by the choice of component and their relative amounts and,

K. Osińska $(\bowtie) \cdot$ D. Czekaj

Department of Materials Science, University of Silesia, 2,

Sniezna St., 41-200 Sosnowiec, Poland

e-mail: katarzyna.osinska@us.edu.pl most importantly, the "connectivity", that is the manner in which the components are interconnected [1].

Composites made of ferroelectric ceramics and polymer are very attractive for applications since they combine properties, which are typical for polymers, like good flexibility and the capability of forming with high electroactivity (piezo- and pyroelectric) responses of electroceramics. As a result, one may be able to develop a new material exhibiting properties tailored to various requirements. As the dielectric permittivity is involved in figures of merit of various physical quantities important for applications (e.g., hydrostatic piezoelectric strain coefficient, electromechanical coupling factor), the knowledge of the dielectric response of the composites is essential $[2,3]$.

Polymer matrix composites containing ferroelectric ceramic powder are widely studied because of their tailored dielectric, thermal, mechanical properties, and easy processing. One of the ferroelectric ceramics like barium titanate $\left(\mathrm{BaTiO}_{3}\right)$ exhibits high dielectric constant (up to 5,000 ) depending on its grain size, purity, crystallographic direction, measuring temperature range, and method of preparation. It has low coefficient of thermal expansion, high thermal, and chemical stability. However, it is brittle and requires high processing temperatures. To overcome these drawbacks, several $\mathrm{BaTiO}_{3}$-filled polymers such as polyetheretherketone, epoxy, polyimide, polystyrene, cyanoethyl ester of polyvinyl alcohol, and polyvinylidene fluoride (PVDF) composites have been studied [4].

The perovskite $(\mathrm{Ba}, \mathrm{Sr}) \mathrm{TiO}_{3}$ (BST) is a intensively investigated ferroelectric due to its unique properties (high permittivity, resistivity, and tunability), which makes it a promising candidate for electronic applications such as multilayer and voltage tunable capacitors, infrared sensors, electrooptic devices, and memories. The mentioned characteristics strongly depend on composition, raw materials, processing, microstructure, temperature, electric field, and frequency, so that, efforts on the BST synthesis are still 
in progress in order to improve its properties [5]. BST is a leadfree, ferroelectric ceramic with high dielectric permittivity. The main objective of many works is to fabricate composites with high dielectric permittivity values in a wide range of temperature, which can be used in energy storage devices [6].

PVDF is a semicrystalline polymer, which exhibits several molecular conformations depending on the method of preparation. PVDF has got two relaxation processes: less intense one, is attributed to the segmental molecular motions occurring above the glass transition temperature $\left(T_{\mathrm{g}}\right)$ and the more intense one, taking place at temperatures lower than $T_{\mathrm{g}}$. The more intense relaxation process is resulted from local motions of small groups in the chain. The existence of any high frequency transformation is limited by the movement of the main chain in the molecule PVDF. Relaxation process occurs at low temperatures is described by Vogel-Fulcher's formula, a relaxation process occurs at higher temperatures by the Arrhenius's formula [7, 8].

The aim of the work was to obtain $\mathrm{Ba}_{0.6} \mathrm{Sr}_{0.4} \mathrm{TiO}_{3}$ (BST60/40) ceramic powder by sol-gel method, to fabricate ceramic-polymer composites of barium strontium titanate BST60/40 and polyvinylidene fluoride PVDF BST// PVDF for concentration of the ceramics phase $c_{\mathrm{v}}=50 \%$ by hot pressing method, to characterize microstructure, thermal and dielectric properties of BST60/40 ceramic powder and BST//PVDF composite.

\section{Experiment}

\section{Material selection}

In this work, the composite BST60/40//PVDF was obtained from $\left(\mathrm{Ba}_{0.6} \mathrm{Sr}_{0.4}\right) \mathrm{O}_{3} \quad(\mathrm{BST} 60 / 40)$ ceramic powder and polyvinylidene fluoride PVDF (SIGMA-ALDRICH, Poznan, $99 \%$ ) powder by hot pressing method at $T=165^{\circ} \mathrm{C}$, $p=120 \mathrm{MPa}$, for volume fraction of BST60/40 ceramic powder $c_{\mathrm{v}}=50 \%$. The $\mathrm{Ba}_{0.6} \mathrm{Sr}_{0.4} \mathrm{TiO}_{3}$ ceramic powder was prepared by the sol-gel method from barium acetate $\left(\mathrm{Ba}\left(\mathrm{CH}_{3} \mathrm{COO}\right)_{2}\right.$, SIGMA-ALDRICH, Poznan, $\left.99 \%\right)$, strontium acetate $\left(\mathrm{Sr}\left(\mathrm{CH}_{3} \mathrm{COO}\right)_{2}\right.$, SIGMA-ALDRICH, Poznan, $99 \%)$, and tetra-butyl titanate $\left(\mathrm{Ti}\left(\mathrm{OC}_{4} \mathrm{H}_{9}\right)_{4}\right.$, SIGMAALDRICH, Poznan, $97 \%$ ) as starting materials.

\section{Manufacturing process}

Figure 1 shows the steps of preparing of BST60/40 ceramic powder.

The basic steps for fabrication of BST60/40//PVDF ceramic-polymer composite by hot pressing technique are given in Fig. 2.

\section{Morphology of samples}

The morphology of BST60/40, PVDF, and BST60/40// PVDF powders and samples were observed by transmission electron microscopy Philips EM 400T (Germany) and scanning electron microscopy HITACHI S-4700 (Japan). Transmission (a) and scanning (b) electron micrographs of BST60/40 ceramic, PVDF polymer, and $50 \%$ BST60/40//PVDF composite are given in Figs. 3, 4, and 5 , respectively.

One can see that polymer grains are arranged around the ceramic grains. The BST60/40 powder is well dispersed in the PVDF polymer matrix without serious powder agglomeration.
Fig. 1 The steps of preparing of BST60/40 ceramic powder: a sol, b gel, c gelating, $\mathbf{d}$ dry gel, e before calcinations, $\mathbf{f}$ after calcinations
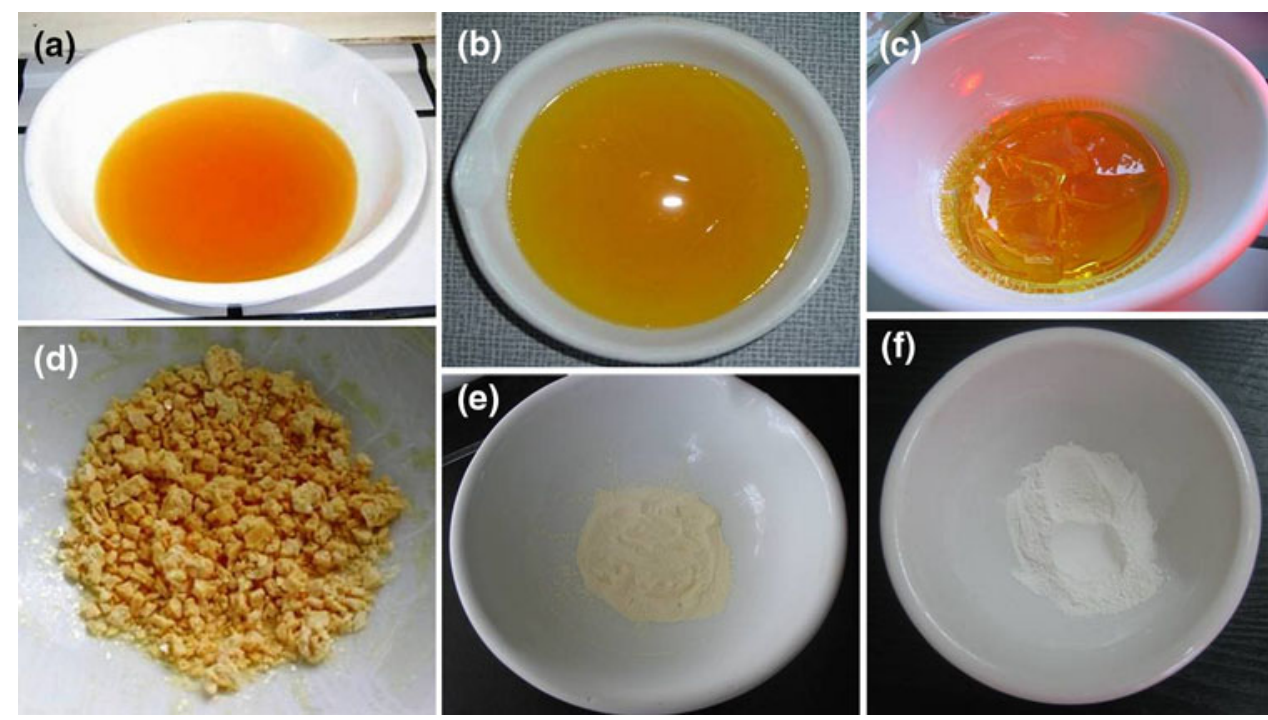
Fig. 2 The basic steps for fabrication of BST60/40//PVDF composite by hot pressing technique

Fig. 3 a TEM micrographs of BST60/40 ceramic powder, b SEM micrographs of BST60/ 40 ceramic sample

Fig. 4 a TEM micrographs of PVDF polymer powder, b SEM micrographs of PVDF polymer sample
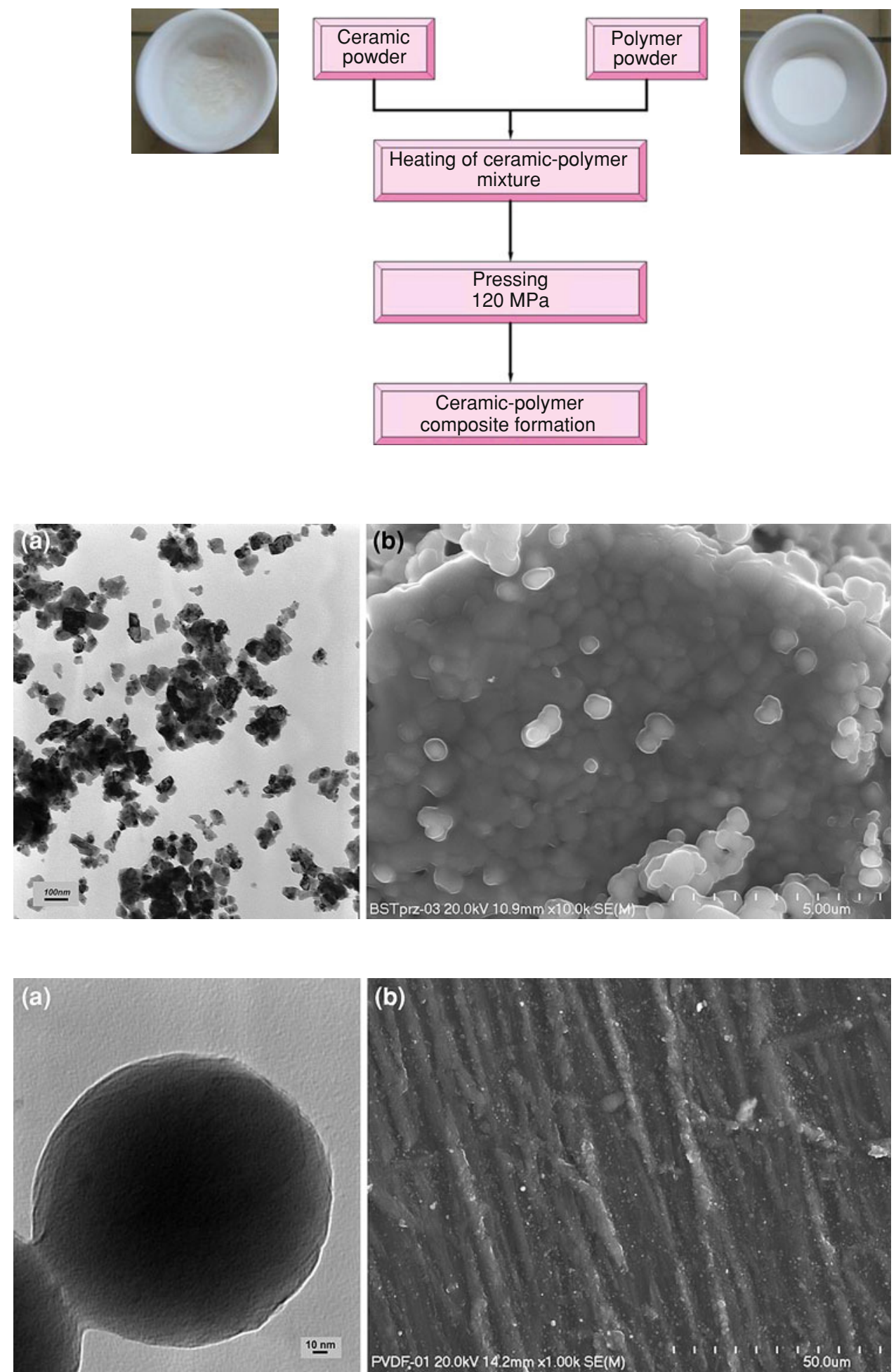

\section{Experimental devices}

The dry gel was analyzed by thermo-gravimetric analysis and by differential thermal analysis (DTA). Simultaneous measurements were executed in air by STA-409 Netzsch analyzer (Germany). Temperature rate was $v=10 \mathrm{deg} \mathrm{min}^{-1}$.
Thermal analysis was carried out in air. The amorphous dry gel of BST60/40 was calcinated at $T=850{ }^{\circ} \mathrm{C}$ for $t=4 \mathrm{~h}$.

For electric measurements, composite sample of $h=$ $1-\mathrm{mm}$ thick and $d=10 \mathrm{~mm}$ in diameter was covered with silver electrodes. The dielectric properties of BST 60/40 ceramics, PVDF polymer, and 50 \%BST60/40// 
Fig. 5 a TEM micrographs of $50 \%$ BST60/40//PVDF composite powder, b SEM micrographs of $50 \%$ BST60/ 40//PVDF composite sample
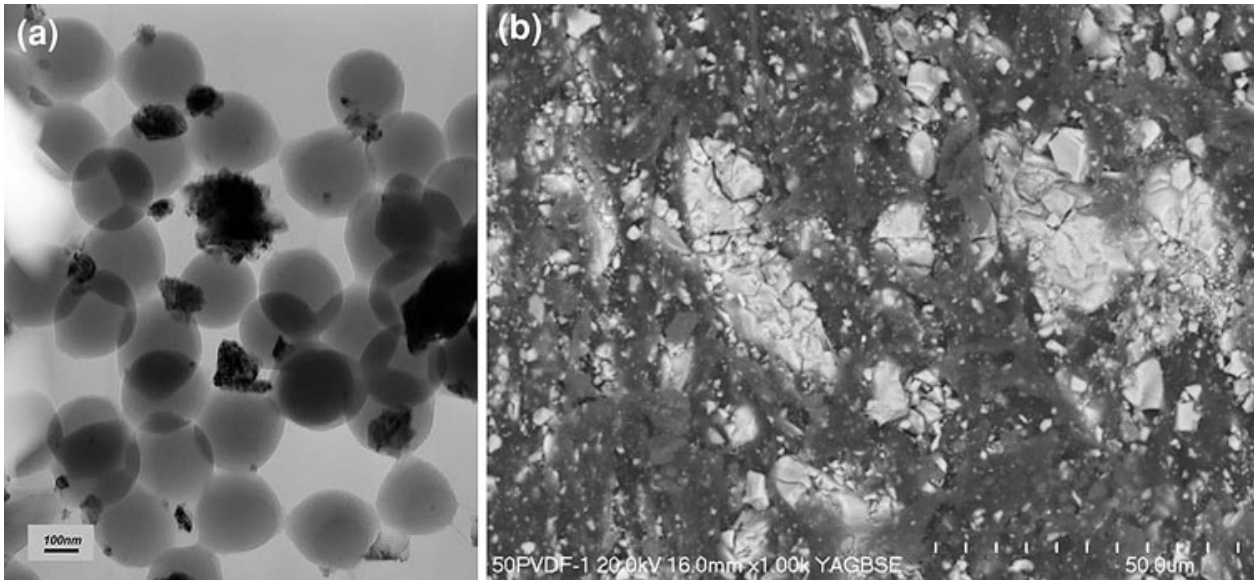

PVDF ceramic-polymer composite were studied with the impedance gain/phase analyzer HP4192A (Great Britain) in the frequency range of $f=10 \mathrm{kHz}-1 \mathrm{MHz}$. The measurements were performed with heating from $T=-50$ to $150{ }^{\circ} \mathrm{C}$ at a rate of $v=1 \mathrm{deg} \min ^{-1}$. Dynamic mechanical properties of PVDF and $50 \%$ BST60/40//PVDF composite were measured by dynamic mechanical thermal analysis DMTA. DMTA allows to designate dependence of the storage modulus $E^{\prime}$ and loss modulus $E^{\prime \prime}$ on temperature, frequency, and time. So that the dependency you can get information about the viscoelastic properties of the material. DMTA method also allows the characterization of relaxation processes occurring during glass transition and determine the range of temperature of glass transition for polymeric materials [9, 10]. Storage modulus $E^{\prime}$ and loss modulus $E^{\prime \prime}$ of PVDF polymer and BST60/40//PVDF composite were measurement by DMTA Q800 analyzer (USA) working in the bending mode (3-point bend), at the frequency $f=100 \mathrm{~Hz}$ and temperature range $\Delta T=$ $-150-150{ }^{\circ} \mathrm{C}$. In this mode, the sample is supported at both ends and force is applied in the middle. 3-point bend is considered a "pure" mode of deformation since clamping effects are eliminated. The $l=50$ and $20 \mathrm{~mm}$ clamps on the Q800 utilize unique low-friction, roller bearing supports that improve accuracy.

\section{Analysis of the results}

Thermal properties

Figure 6 shows thermal analysis curves of BST60/40 dry gel, respectively, before calcination (a) and after calcination (b). One can see from Fig. 6 that dried gel powder exhibited a large total mass loss $\Delta m \approx 47 \%$. The analyzes show three stages of mass loss.

The peak at around $T=120{ }^{\circ} \mathrm{C}$ on the DTG curve and corresponding mass loss $\Delta m_{1} \approx 15 \%$ on the TG curve, are due to the evaporation of solvents. Below $T=300{ }^{\circ} \mathrm{C}$, the first drop corresponds to the evaporation of the solvent.

The second notable mass loss $\Delta m_{2} \approx 21 \%$ was detected at $T \approx 337{ }^{\circ} \mathrm{C}$. The mass loss is probably due to the decomposition of organic additives in the gel. The peak on the DTG curve matched a large exothermic peak in the DTA curve.

The exothermic peak around $T \approx 400{ }^{\circ} \mathrm{C}$ and relatively broad exothermic features at $T \approx 650{ }^{\circ} \mathrm{C}$ on the DTA curve of dried gel, could be due to crystallization of various intermediate phases. It is known that for sol-gel-derived barium titanate several intermediate phases exist prior to the transformation of the amorphous phase into the perovskite phase. The nature of these intermediate phases and the crystallization sequence depends upon the precursors used [11].

The third notable drop between $T=600$ and $800{ }^{\circ} \mathrm{C}$ corresponds to a peak of the DTG curve at about $T=718.5^{\circ} \mathrm{C}$. The mass loss originates from the release of various side products during alcoxolation and oxolation.

Figure $6 \mathrm{~b}$ shows that after calcination no thermal effects take place in BST60/40 powder. On the basis of thermal analysis, the temperature calcination was chosen $T=850{ }^{\circ} \mathrm{C}$ for dried gel of BST60/40 powder.

\section{Dielectrical properties}

Dependence of the dielectric constant $\varepsilon^{\prime}$ (a) and dielectric loss factor $\varepsilon^{\prime \prime}$ (b) on temperature for BST60/40 ceramic at $f=100 \mathrm{kHz}$ is given in Fig. 7. It can be seen from Fig. 7 that the three peaks originated from cubic-tetragonal, tetragonal-orthorhombic, and orthorhombic-rhombohedral phase transition.

Figure 8a, b, respectively, shown dielectric constant $\varepsilon^{\prime}$ and dielectric loss factor $\varepsilon^{\prime \prime}$ of PVDF for $f=50 \times 10^{3} \mathrm{~Hz}$, $f=100 \times 10^{3} \mathrm{~Hz}, f=500 \times 10^{3} \mathrm{~Hz}$, and $f=1 \times 10^{6} \mathrm{~Hz}$. A cusp-like behavior in the frequency and temperature dependence of the dielectric constant $\varepsilon^{\prime}(f, T)$ in the 
Fig. 6 a Thermal analysis data of BST60/40 dry gel before calcinations, b thermal analysis data of BST60/40 dry gel after calcinations

\section{(a)}

$\begin{array}{ll}\text { TG/\% } & \text { DTA } / 10^{-6} \mathrm{~V} / 10^{-3} \mathrm{~g} \\ 0.00 & \end{array}$

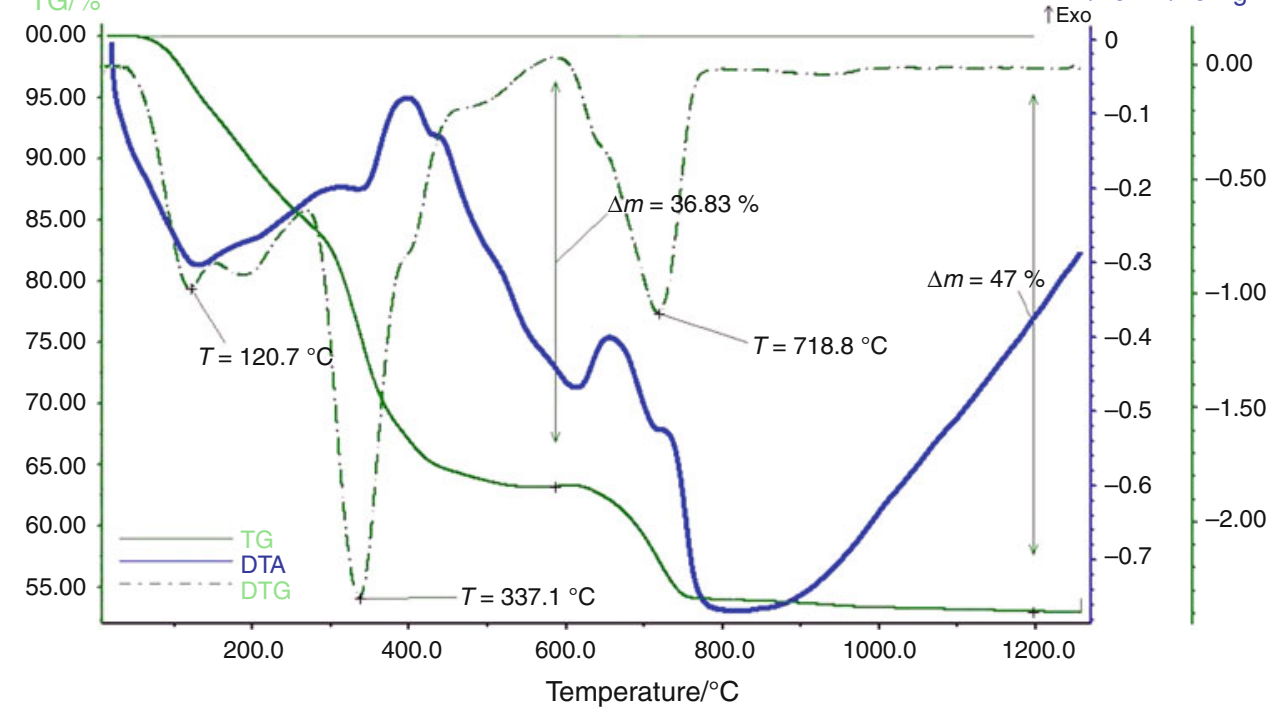

\section{(b)}

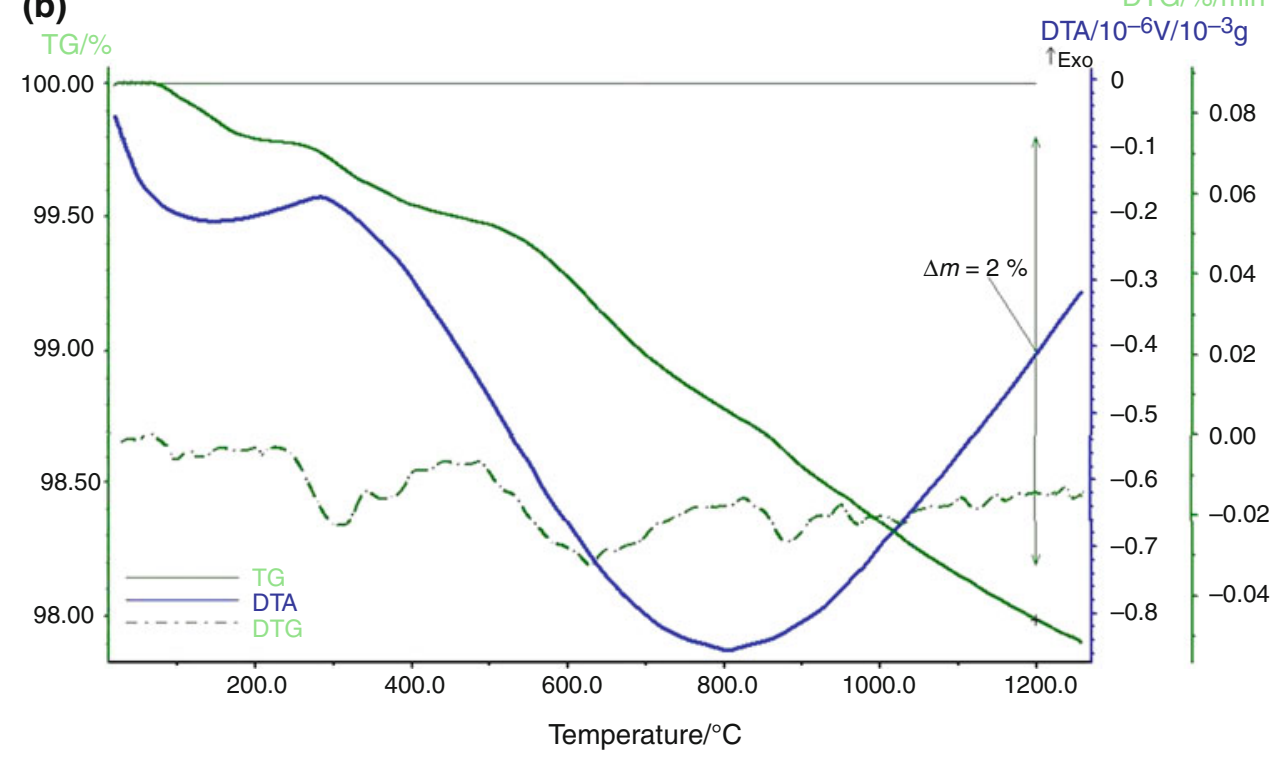

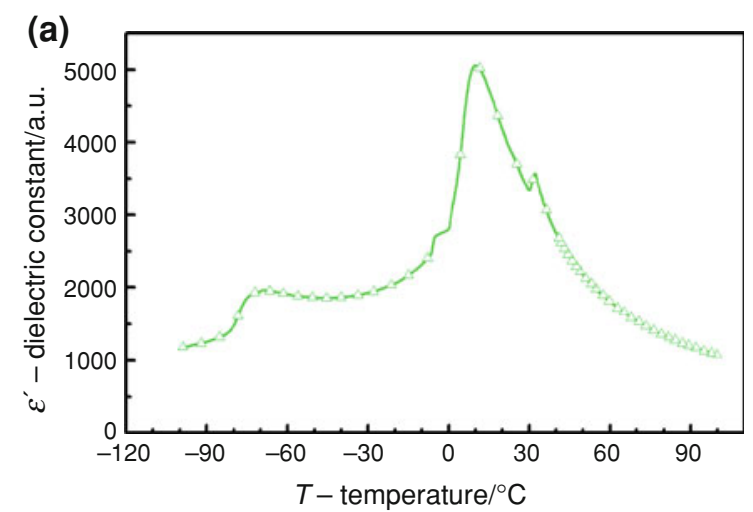

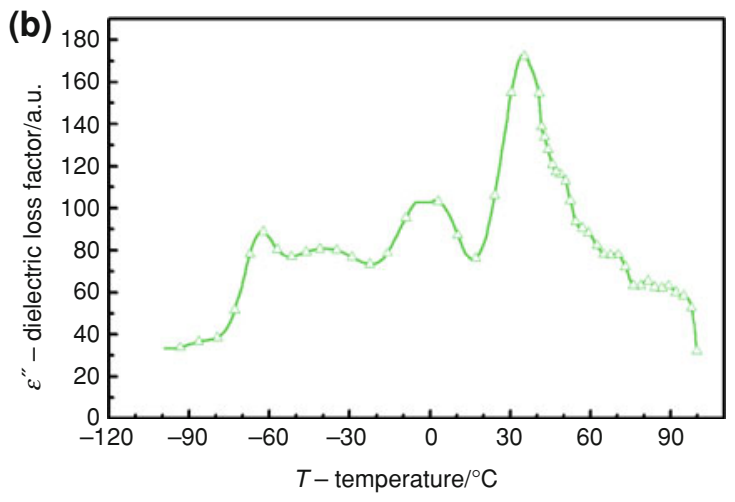

Fig. 7 Temperature dependence of the dielectric constant $\varepsilon^{\prime}$ (a) and dielectric loss factor $\varepsilon^{\prime \prime}$ (b) of BST60/40 ceramic at $f=100 \mathrm{kHz}$ 

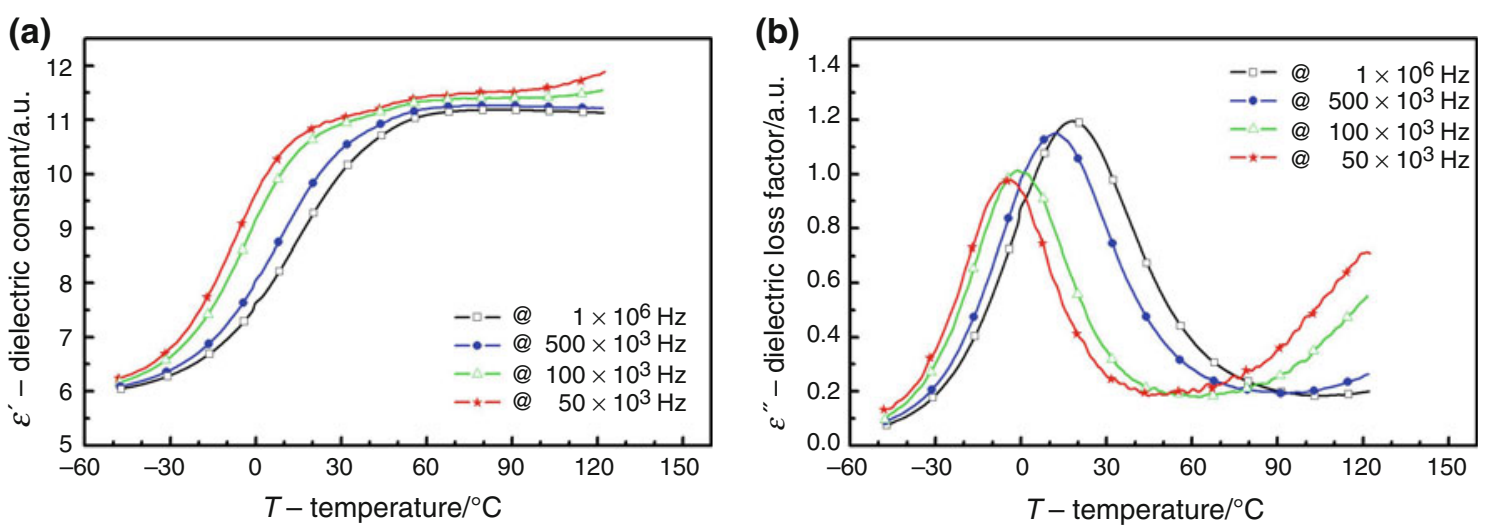

Fig. 8 Temperature dependence of the dielectric constant $\varepsilon^{\prime}$ (a) and dielectric loss factor $\varepsilon^{\prime \prime}$ (b) of polyvinylidene fluoride PVDF
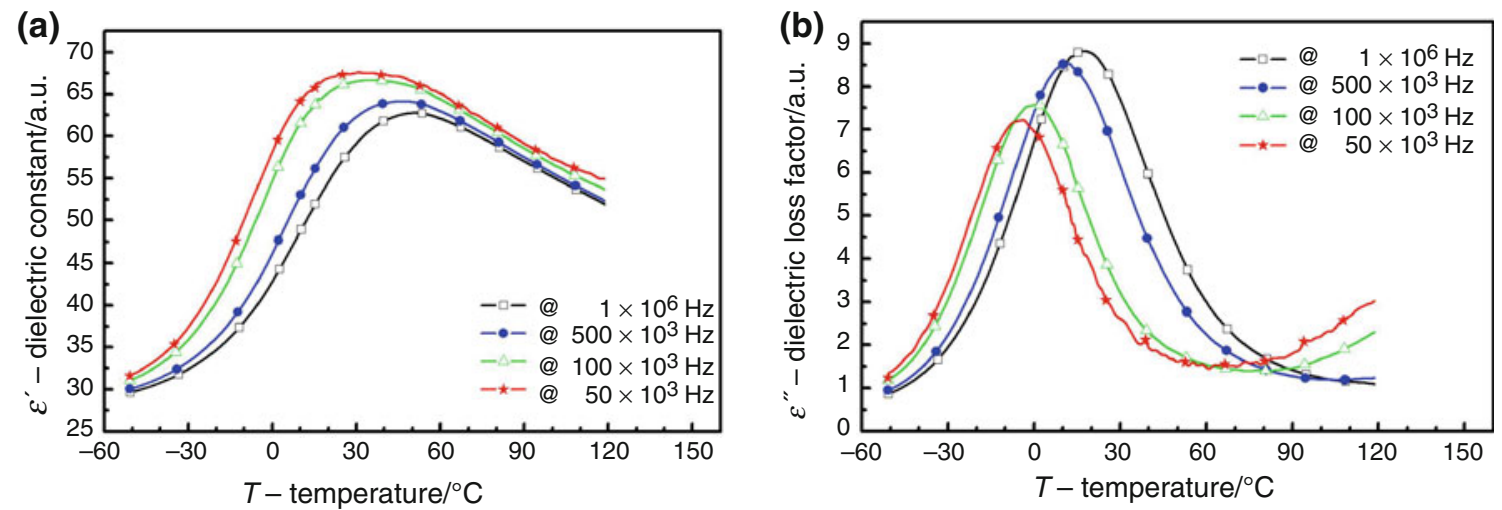

Fig. 9 Temperature dependence of the dielectric constant $\varepsilon^{\prime}$ (a) and dielectric loss factor $\varepsilon^{\prime \prime}$ (b) of 50\%BST60/40//PVDF composite
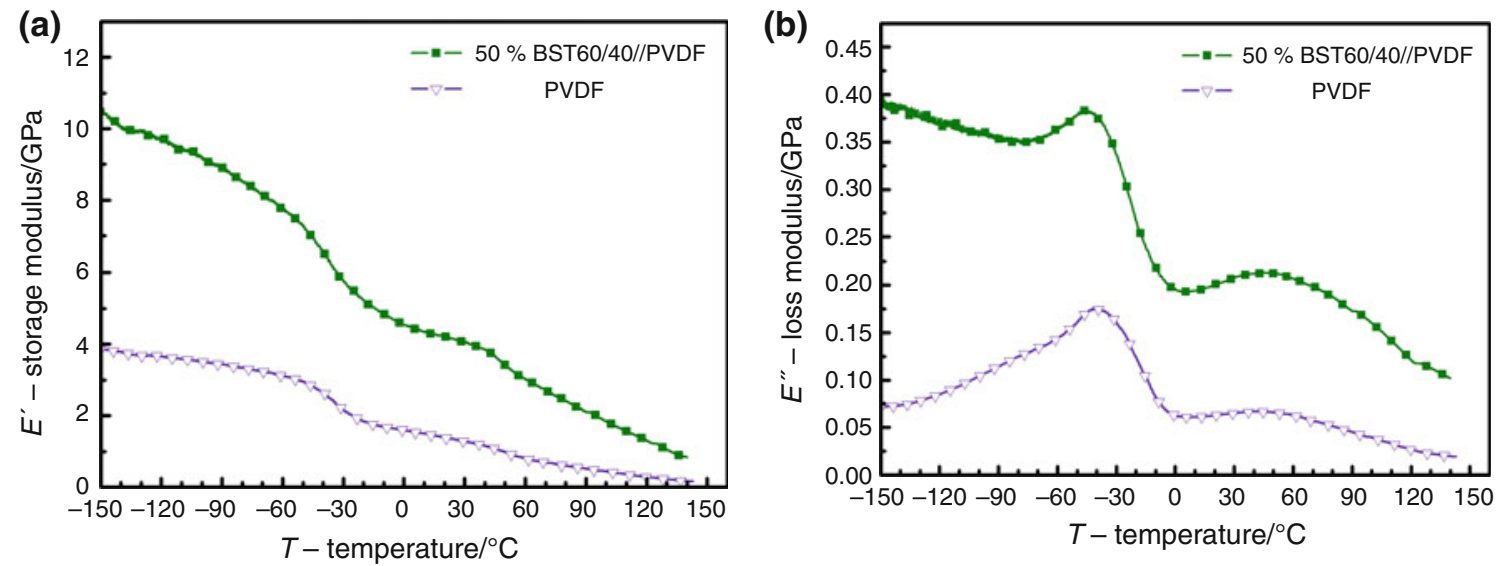

Fig. 10 Comparison of temperature dependence of the storage modulus $E^{\prime}(\mathbf{a})$ and loss modulus $E^{\prime \prime}(\mathbf{b})$ for PVDF polymer and 50 \%BST60/40// PVDF composite

temperature range of $T=-50$ to $60{ }^{\circ} \mathrm{C}$ accompanied by absorption maxima increasing and shifting towards higher temperatures with increasing frequency is related to a freezing of dipolar motion in the amorphous region. A dispersive $\varepsilon^{\prime}$ anomaly and absorption maxima shifting toward higher temperatures and increasing with increasing frequency in the range of $T=60-100{ }^{\circ} \mathrm{C}$ are ascribed to wide angle oscillations of dipoles attached to the chain, followed by their rotation with the main chain co-operation appearing in the crystalline phase. 
The dielectric absorption behavior apparent in the range of $T=-50$ to $60{ }^{\circ} \mathrm{C}$ is characteristic of the static dipolar freezing of dipolar motion in the absence of a long-range correlation. Dielectric absorption in the crystalline phase of the polymer observed in the temperature range of $T=60-100{ }^{\circ} \mathrm{C}$ is described by the oscillation motion of the VDF groups $[2,12]$.

Temperature dependence of the dielectric constant $\varepsilon^{\prime}$ (a) and dielectric loss factor $\varepsilon^{\prime \prime}$ (b) of $50 \% \mathrm{BST} 60 / 40 / / \mathrm{PVDF}$ composite at $f=50 \times 10^{3} \mathrm{~Hz}, f=100 \times 10^{3} \mathrm{~Hz}, f=500 \times$ $10^{3} \mathrm{~Hz}$, and $f=1 \times 10^{6} \mathrm{~Hz}$ is shown in Fig. 9. One can see that the addition of ceramic phase in the polymer will change the nature of the curve $\varepsilon^{\prime}(T)$. Changing the speed of the curve rise, there is a maximum of the $\varepsilon^{\prime}(T)$ and the dielectric constant increases with increasing of the frequency. Values of the dielectric constant $\varepsilon^{\prime}$ and dielectric loss factor $\varepsilon^{\prime \prime}$ increases with increasing of the temperature to $\varepsilon_{\mathrm{m}}^{\prime}$ and $\varepsilon_{\mathrm{m}}^{\prime \prime}$ and next decreasing. In the low temperature range, the dielectric response of the composites is determined by the anomaly characteristic in the glass transition of the polymer, whereas in the high temperature range the relaxation related to the wide angle oscillation of the polymer polar groups followed by their rotation with main chain co-operation is dominant. The addition of the ceramics only slightly changes the dynamics of the $\alpha$ process in the polymer. The addition of the ceramics resulted in the increase thermal strength of the composites.

\section{Dynamical properties}

Figure 10a, b, respectively, shown comparison of temperature dependence of the storage modulus $E^{\prime}$ (a) and loss modulus $E^{\prime \prime}$ (b) for PVDF polymer and $50 \% \mathrm{BST} 60 / 40 / / \mathrm{PVDF}$ composite in the temperature range of $T=-150$ to $150{ }^{\circ} \mathrm{C}$.

The addition of BST60/40 ceramic phase in the PVDF polymer changes character $E^{\prime}(T)$ and $E^{\prime \prime}(T)$ curves and increases the values of the storage modulus $E^{\prime}$ and loss modulus $E^{\prime \prime}$. Values of the $E^{\prime}$ decreases with increasing of the temperature. Can be observed two maxima in the curve $E^{\prime \prime}(T)$. The first maximum is in the range of $T=-60$ to $-30{ }^{\circ} \mathrm{C}$. This maximum is characterized by glass transition in the polymer. The second maximum, in the range of $T=-10$ to $0{ }^{\circ} \mathrm{C}$, due to relaxation processes associated with the wide angle and rotational oscillations of polar groups of the polymer [13]. The movement of parts of the polymer chains in the ceramic-polymer composite is impeded, because of the presence of the ceramic phase. This is manifested less fuzzy maximum on the curve $E^{\prime \prime}(T)$.

\section{Conclusions}

In this study, we have fabricated the $50 \% \mathrm{BST} 60 / 40 / / \mathrm{PVDF}$ ceramic-polymer composites using sol-gel-derived barium strontium titanate $\mathrm{Ba}_{0.6} \mathrm{Sr}_{0.4} \mathrm{TiO}_{3}$ fine powder and PVDF polymer powder by using a hot pressing method. Dried gel powder of BST60/40 exhibited a large total mass loss $\Delta m \approx 47 \%$. The analyzes show three stages of mass loss: at $T=120,337$, and $718{ }^{\circ} \mathrm{C}$. Three peaks originated from cubic-tetragonal, tetragonal-orthorhombic, and orthorhombic-rhombohedral phase transition can be seen for BST60/40: at $T=-70,0$, and $10^{\circ} \mathrm{C}$. Values of the dielectric constant $\varepsilon^{\prime}$ and dielectric loss factor $\varepsilon^{\prime \prime}$ increases with increasing of the temperature to $\varepsilon_{\mathrm{m}}^{\prime}$ and $\varepsilon_{\mathrm{m}}^{\prime \prime}$ and next decreasing. In the low temperature range, the dielectric response of the composites is determined by the anomaly characteristic in the glass transition of the polymer, whereas in the high temperature range the relaxation related to the wide angle oscillation of the polymer polar groups followed by their rotation with main chain co-operation is dominant.

The addition of the ceramic phase to a clean polymer substantially alters the course of temperature dependence of dielectric constant $\varepsilon^{\prime}$, dielectric loss factor $\varepsilon^{\prime \prime}$, storage modulus $E^{\prime}$ and loss modulus $E^{\prime \prime}$. The addition of the ceramics only slightly changes the dynamics of the $\alpha$ process in the polymer. The addition of the ceramics resulted in the increase thermal strength of the composites. The movement of parts of the polymer chains in the ceramic-polymer composite is impeded, because of the presence of the ceramic phase.

Open Access This article is distributed under the terms of the Creative Commons Attribution License which permits any use, distribution, and reproduction in any medium, provided the original author(s) and the source are credited.

\section{References}

1. Moulson AJ, Herbert JM. Electroceramics: materials, properties, applications. London/New York/Sydney: Wiley; 2003.

2. Hilczer B, Kułek J, Markiewicz E, Kosec M, Malic B. Dielectric relaxation in ferroelectric PZT-PVDF nanocomposites. J NonCryst Solids. 2002;305:167-73.

3. Uchino K. Ferroelectric devices. New York: Marcel Dekker Inc; 2000.

4. Goyal RK, Katkade SS, Mule DM. Dielectric, mechanical and thermal properties of polymer $/ \mathrm{BaTiO}_{3}$ composites for embedded capacitor. Compos B. 2013;44:128-32.

5. Ianculescu A, Berger D, Viviani M, Ciomaga CE, Mitoseriu L, Vasile E, Drăgan N, Crişan D. Investigation of $\mathrm{Ba}_{1-x} \mathrm{Sr}_{x} \mathrm{TiO}_{3}$ ceramics prepared from powders synthesized by the modified Pechini route. J Eur Ceram Soc. 2007;27:3655-8.

6. Adikary SU, Chan HLW, Choy CL, Sundaravel B, Wilson IH. Characterisation of proton irradiated $\mathrm{Ba}_{0.65} \mathrm{Sr}_{0.35} \mathrm{TiO}_{3} / \mathrm{P}(\mathrm{VDF}-$ TrFE) ceramic-polymer composites. Compos Sci Technol. 2002;62:2161-7.

7. Kepler RG, Nalwa HS. Ferroelectric polymers: chemistry, physics and applications. New York: Marcel Dekker Inc; 1995.

8. McCrum NG, Read BE, Willims G. Anelastic and dielectric effects in polymeric solids. London/New York/Sydney: Wiley; 1967. 
9. Danch A. The glass transition. J Therm Anal Calorim. 2006;84:663-8.

10. Danch A. Some comments on nature of the structural relaxation and glass transition. J Therm Anal Calorim. 2008;91:733-6.

11. Majumder SB, Jain M, Martinez A, Katiyar RS, Van Keuls FW, Miranda FA. Sol-gel derived grain oriented barium strontium titanate thin films for phase shifter applications. J Appl Phys. 2001;90:896-903.
12. Osinska K, Adamczyk M, Dzik J, Bernard H, Czekaj D. Fabrication and characterization of BST60/40//PVDF ceramic-polymer composite. Arch Metall Mater. 2011;56:1083-91.

13. Danch A. Effect of supermolecular structure changes on the glass transition of polymer. J Therm Anal Calorim. 2001;65:525-35. 